\title{
Optimization of side stream filters of blow-down water in cooling water system
}

Optimización de los filtros de flujo lateral de agua de purga en

el sistema de agua de enfriamiento

Author:

Amir Hossein Beigi ${ }^{*}$

Ali Mousavi ${ }^{2}$

Dani Sadr Hosseini ${ }^{3}$

\section{SCIENTIFIC RESEARCH}

How to cite this paper:

Beigi A. H., Mousavi A. and Sadr Hosseini H ., Optimization of side stream filters of blow-down water in cooling water system, Iran. Innovaciencia 2020; 8 (1): 1-7. DOI : http://dx.doi.org/10.15649/2346075X.1002

\section{Reception date:}

Received: 01 May 2020

Accepted: 01 August 2020

Published: 01 December 2020

Keywords:

Continuous oily contaminant (COC), Potential oily contaminant (POC), Total dissolved solids (TDS), Total solid substances (TSS), Reverse Osmosis system, Side stream filter

\begin{abstract}
Introduction Cooling towers are the main parameters for oil and gas industries. The water that circulates the system will pass through heat exchangers and surface condenser of compressor. Cooling towers operate outside; there is a high chance of debris entering the system and water via wind which therefore could lead to fouling, scaling and corrosion. In order for cooling towers to perform at high efficiency, the water has to be clean. Filtration package are the key for solving this matter. Material and Methods In this thesis, a new filtration package for Marjan petrochemical company has been proposed. In this design the blow down water of the cooling tower will be filtered via first a side stream filtration unit. Results It which will decrease the TSS of the water and then enters a Reverse Osmosis package which will reduce the TDS of the water. From the Hysys simulation, it has been proven that this system will produce $63 \mathrm{~m} 3 / \mathrm{hr}$ pure water and $37 \mathrm{~m} 3 / \mathrm{hr}$ brain water. Conclusion The compositions of these water are $97 \%$ pure water and 3\% debris, $96 \%$ debris and $4 \%$ water respectively. This showed that the filtration package decreased the TDS of the water to $4 \mathrm{ppm}$ which is the specification of the make-up water of cooling tower. Financially, when there is no package installed, Marjan has to send COC and POC waters to Mobin Company for filtrations and then buy the $\mathrm{RO}$ water.
\end{abstract}

1* Master of Science, Mechanical Engineering, Energy conversion, Sharif University of Technology, International Campus, Kish Island, Iran, Email Address: amir 1992@hotmail.co.uk

2 Department of Engineering and Science, Sharif University of Technology- International Campus, Kish Island, Iran, Email Address: moosavi@sharif.ir

다(1)(3)

CC BY-NC 4.0

3 Department of Engineering and Science, Sharif University of Technology- International Campus, Kish Island, Iran, Email Address: sadr@kish.sharif.edu 


\section{INTRODUCTION}

In Oil and gas industries, especially petrochemical, water plays an essential role for either cooling or heat exchange. The main job of cooling tower is to dissipate heat into environment through evaporation. In cooling tower, high temperature water produced from the heat exchangers, enters the tower and spreads evenly at the top. As the water flows down the cooling tower, the equipment fill spreads it over a vast area to increase the water-air contact, therefore improving heat transfer via evaporation [1]. Air in cooling towers, is passed alongside or counter at present with water. The heat that is gained by air is the heat that is lost by water. In cooling towers the effectiveness depends on various factors, these are water and air flow rates and working temperature of the tower.

Various types of cooling tower exist, which are natural draft, forced draft and induced draft cooling towers. Regarding the process of cooling tower, the schematic process of basic cooling tower is shown in The water consists of various minerals, known as dissolved solids. When evaporation occur in cooling tower, the remaining water will be rich in minerals. When the water evaporates the level of the remaining water in the cooling tower decreases, therefore more water which is usually referred to as make up water will be added to the system. This will increase the dissolved solids, therefore the concentration of solids in water will be higher than the valid amount. The solids become more prone to attaching themselves to the pipe walls, heat exchanger and other equipment that the loop of water of cooling tower is been circulated. To stay below the acceptance level of concentration, portion of the concentrated cooling tower water needs to be discharged from the cooling tower, this is called blow-down water. The amount of blow-down needed depends on the system use and the quality of the fresh water supply [1].

\section{Hot Water In}

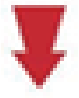

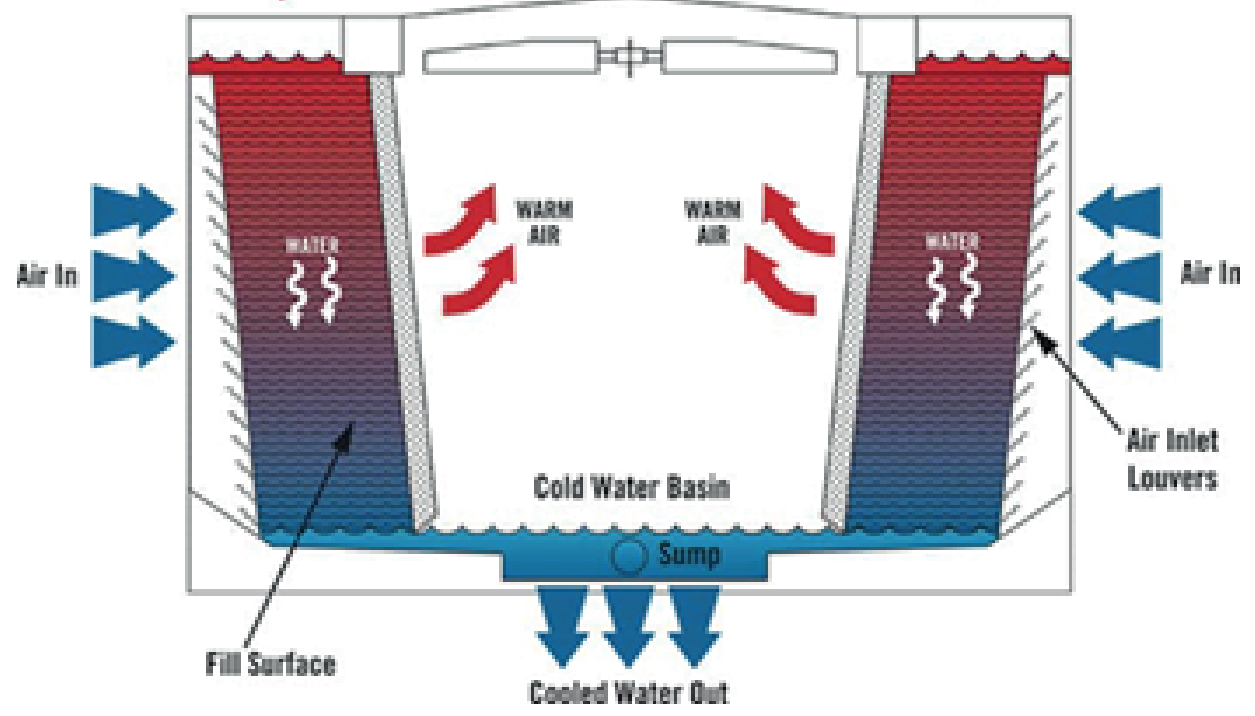

Figure 1. Cooling water syste[1]

\section{SIDE STREAM FILTERS}

"Side stream filtration system reduce suspended solids and debris in the cooling water system, which leads to less fouling in the system. Decreasing suspended solids can also help reduce biological growth in the system because the suspended solids are a good source of food for microbiological organisms. Decreasing biological growth in turn helps to reduce microbiologically influenced corrosion. In addition, scaling can be reduced from side stream filtration by limiting fouling and corrosion by-products, 
which can also contribute to scale formation on the heat exchange surfaces. Effectively managing these conditions through filtration can optimize system performance, often resulting in moderate to significant energy and water savings[1].

Full flow and side stream filtration are the two most common methods used to filter the water that is pumped into the circulation systems. Full flow filtration uses a filter installed after the cooling tower on the discharge side of the pump. This filter continuously filters all of the recirculating system water in the system. Inherently, the filter must be sized to handle the system's design recirculation rate. Side stream filtration, on the other hand, continuously filters a percentage of the flow instead of the entire flow. It can be a cost-effective alternative to full flow filtration that can easily improve the water quality to reduce water consumption and ensure efficiency of the cooling systems. And unlike full flow filtration, side stream filtration systems can be cleaned while the cooling systems are online, avoiding the need for planned downtime (BAC 2012)" [2].

Side stream filters are introduced to the system of cooling to remove any debris from the circulated water. This filtration system continuously filter a portion of the cooling water and return filtered to the cooling tower basin [3,4]. A schematic of how the side stream filter works is shown in Error! Reference source not found.

These systems remove suspended solids, organics, and silt particles for a portion of the water system on a continuous basis, reducing the likelihood of fouling and bio growth, which helps to control other issues in the system such as scaling and corrosion. This improves system efficiency and often reduces the amount of water blown down[5].

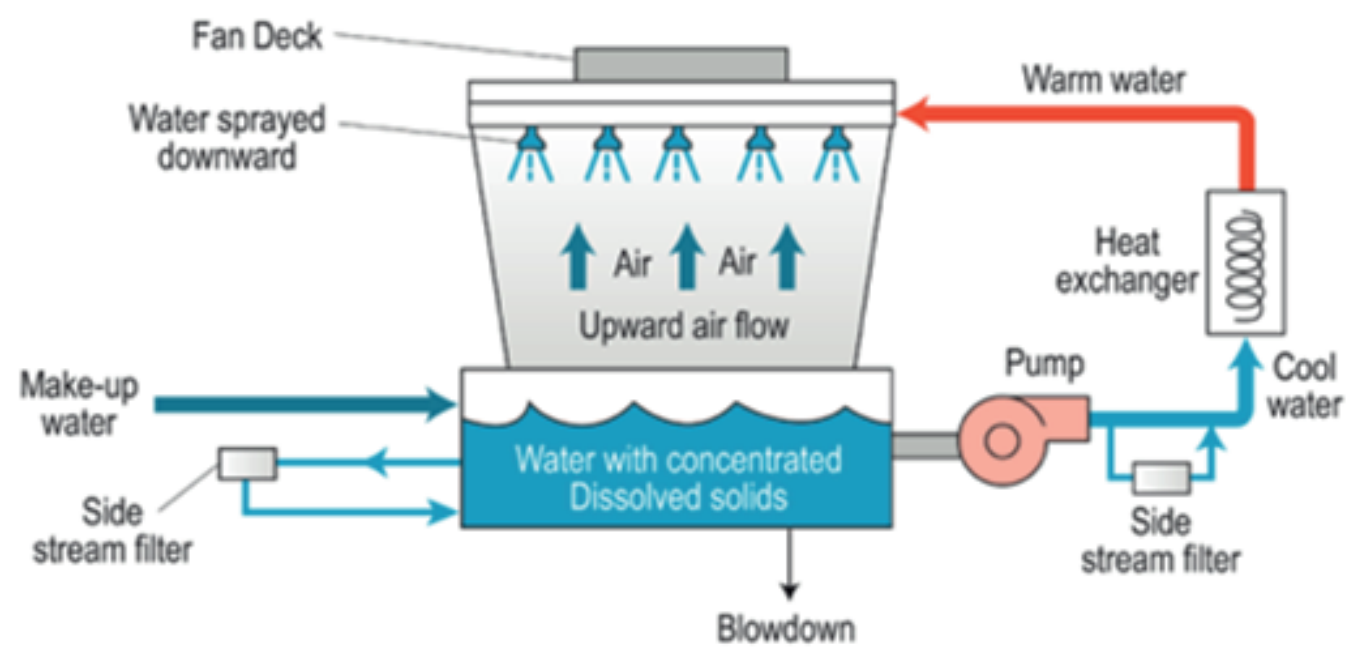

Figure 2. Side stream filtration schematic[5]

\subsection{Make-up Water}

The cooling processes of equipment usually happen when there is water circulating in them. Water is the most common cooling medium due to its high heat capacity and also the availability of water.

From previous studies, it has been mentioned that in water there are concentrated substances that can harm the equipment if they are not filtered. These are total solid substances (TSS), and total dissolved substances (TDS). However, other parameters such as conductivity, PH, chemical oxygen demand (COD) and biological oxygen demand (BOD) play an essential role in the cooling tower water that will be circulating through the loops of the system. The 
efficiency of the system is related to how well these parameters are controlled [6].

The chemical, physical and bacteriological characteristics of the water need to be monitored in order to determine if the water quality is adequate for the cooling process and if the treatment is sufficient. If the water quality is not the desired one, the pre-treatment steps need to be changed. One of the processes that need to be controlled is the scale formation. Scale deposition will inhibit the efficiency of the heat transfer elements and also have a positive impact on the bacteriological growth. At the beginning of the industrial revolution many boilers exploded because of the precipitated scale on the heating elements. Scale control is normally done with the $\mathrm{pH}$ control and addition of chemicals[7].

\subsection{Blow-down Water}

The blowdown water is estimated to be $3 \%$ of the total

$$
\text { Cycle of concentration }=\left[\frac{\text { Concentration in blowdown }}{\text { Concentration in make }- \text { up }}\right]
$$

Calcium, magnesium, silica, carbonate, bicarbonate and sulphate ions are the parameters which have to be kept in mind. The chemical choice for the $\mathrm{pH}$ control should also be influenced by the makeup water characteristics. Sulfuric acid dosing for the adjustment of the $\mathrm{pH}$ should be done so that the calcium sulphate concentration will not exceed the imposed limit. Blowdown is also used for the removal of the suspended solids caused by internal precipitation, external contaminants or soluble salts. If proper chemical and physical treatment is applied to control scale formation, corrosion and microbial growth, the rate of blowdown can be reduced.

\section{ASPEN HYSYS SIMULATION}

Hysys aspen program is a chemical and fluid dynamic process simulator used to mathematically model processes. Hysys is able to perform many of the core calculations of chemical engineering, volume of the cooling tower water. The blowdown water depends of the degree of concentration in the system, or the cycle of concentration. When the concentration of make-up water increases above a certain limit, in order to protect the efficiency and life expectancy of components, blowdown water discharges. Water cycles through the system and will go back to the cooling tower, however the number of cycles that is required for the system depends on variables such as water characteristics, tower design, operating condition and the treatment[8].

The cycle of concentration can also be defined as the ratio between the chloride concentration in the recirculating water and chloride concentration in the make-up water. The composition of the makeup water determined the cycles of concentration. The cycle of concentration can be derived by using equation 1.

and fluid mechanics concerned with mass balance, energy balance, heat transfer, mass transfer, chemical kinetics, and pressure drop. This simulator is extensively used for steady state and dynamic simulation, process design, performance modelling, and optimization.

In Hysys aspen, composition and state of the materials will be defined and the equipment that the stream fluid will cycle through the system will be simulated. In order to use this software, first the program has to be verified so the results of the programs are valid scientifically. In order to verify the program, 3 different stream lines of Marjan petrochemical plant have been simulated; these streams were simulated by using the process flow diagram of the site. The reason that 3 lines were simulated, were to increase the probability of having lower error in the proposed design. The error of the software is calculated by using below. Equation 2, error 
Error $=\left[\frac{\text { Experimental value }- \text { Theoretical value }}{\text { Theoretical Value }}\right] \times 100$

\subsection{Streamlines}

From the process flow diagram of Marjan petrochemical company, different areas of site have been simulated in Hysys and it has been shown. The three streams that were selected for calculating the error of the program is; Line 10, fuel gas to stack stream, and stream 27. The hypothesis is that the error of the Hysys compare with PFD should be equal or less than $5 \%$ level.

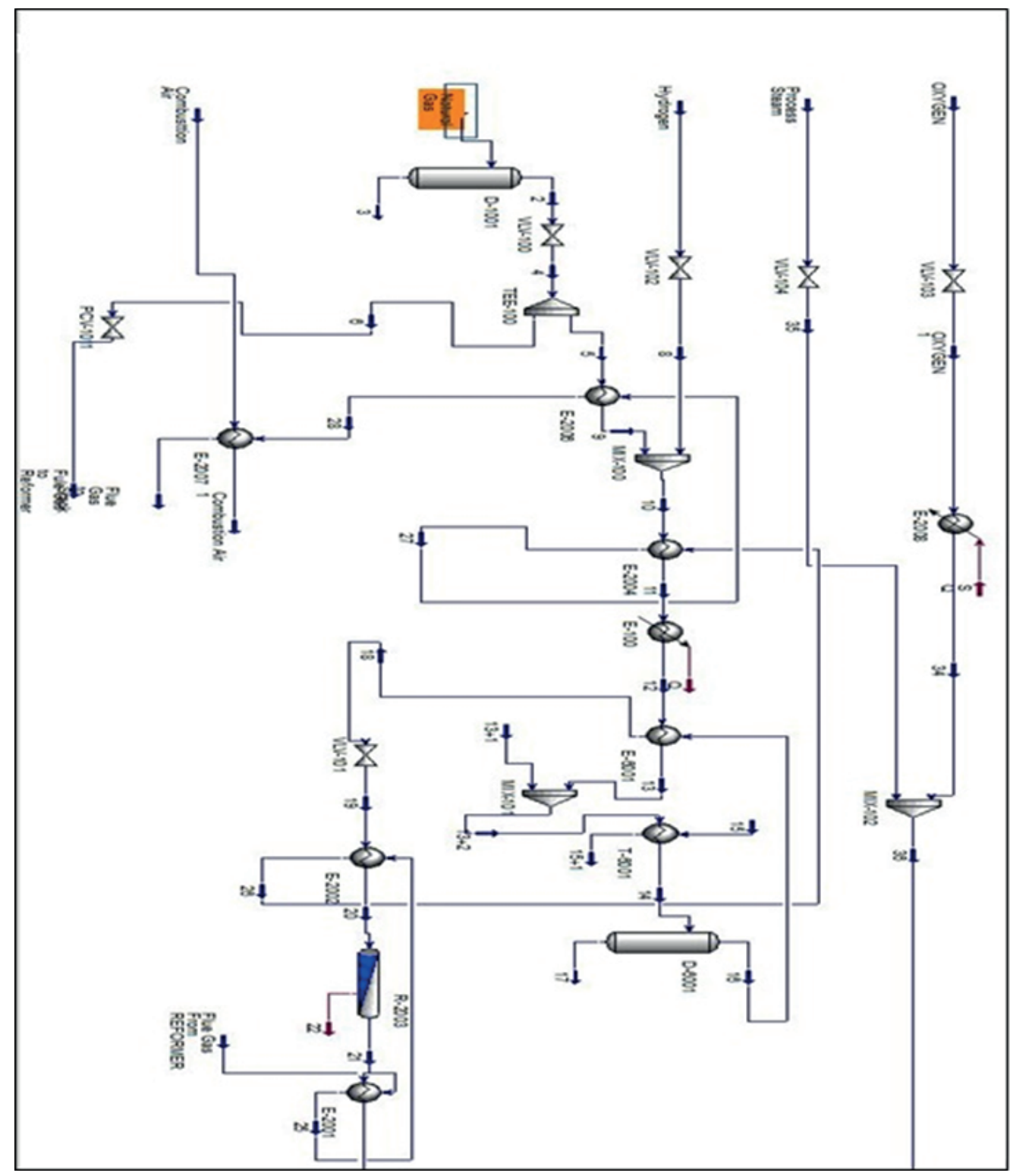

Figure 3. some of the streams were simulated and shown.

However, in order to calculate the error of this before have been selected. Now, the values that were program, the three streams that were mentioned obtained from the Hysys program and Process flow diagram are shown in Table (1). 
Table 1. Temperature results

\begin{tabular}{ccc}
\hline Lines & PFD & HYSYS \\
\hline Line 10 & $246{ }^{\circ} \mathrm{C}$ & $246.3{ }^{\circ} \mathrm{C}$ \\
Stream fuel gas to stack & $150.0{ }^{\circ} \mathrm{C}$ & $153.5{ }^{\circ} \mathrm{C}$ \\
Stream no. 27 & $348{ }^{\circ} \mathrm{C}$ & $362.8{ }^{\circ} \mathrm{C}$ \\
\hline
\end{tabular}

Error Calculation

\author{
Error line $10=0.13 \%$ \\ Error fuel to stack $=2.2 \%$ \\ Error stream $27=4.07 \%$
}

By deriving the error for each line, it can be seen that the error for all the streams is less than $5 \%$ level. Therefore, the hypothesis is correct and the values that been calculated by Hysys are valid and this proofs that the simulator is verified and the results of this Article will be within the error of less than $5 \%$. Design of Side Stream Filter for Blow-down Water

\subsection{Water characteristics}

Cooling water will cycle 8 times through the closed loop and through boilers, heat exchangers and other equipment. Therefore, when the cycle of water is finished, the substances that neither are nor suspended neither dissolved will be higher than normal rate. These parameters are called Total Dissolved Solids and Total Suspended Solids, TDS and TSS. With the help of the designed system, the value of TSS and TDS will be reduced significantly and improve and optimize the cooling tower system of the plant. Now in order to carry out this design first, the current values of TDS and TSS of blowdown water and make up water will be written.

The aim is to reduce the TSS and TDS value and introduce it to the cooling tower as make-up water.

The analysis of blow down water, saturator water, and make-up water have been analysed and shown in below.

Table 2. Analysis of cooling tower water

\begin{tabular}{|c|c|c|c|}
\hline Test & Blow-down pit (ppm) & Saturator (ppm) & Make-up water (ppm) \\
\hline $\mathrm{PH}$ & 7.6 & 9.1 & 8.2 \\
\hline T-Phosphate & 3.8 & 6.5 & - \\
\hline O-Phosphate & nil & 5.6 & - \\
\hline $\mathrm{Fe}^{1}$ & 1.6 & - & - \\
\hline TSS & 27 & 24 & 0 \\
\hline Chlorine & nil & - & 3 \\
\hline Chloride & 78 & - & - \\
\hline TDS & 180 & 450 & 4 \\
\hline $\mathrm{EC}(\mu \mathrm{s} / \mathrm{cm})$ & 340 & - & 8 \\
\hline Alkalinity & 18 & - & - \\
\hline $\mathrm{Ca}-\mathrm{H}$ & 72 & - & - \\
\hline TH & 75 & - & - \\
\hline TBC & $<10^{3}$ & - & \\
\hline
\end{tabular}


The aim of optimising the cooling water system is to reduce the TSS and TDS value of blow-down water and getting those values as close as possible to the make-up water specification that has been shown above.

\section{CONCLUSION}

The combination of process and environmental factors can be contribute to four primary treatment concerns encountered in open-recirculation cooling systems: Corrosion, scaling, fouling, and microbiological activity. The mentioned treatment concerns are inter-related such that reducing one can have severe reduction on the impact of the other three treatments.

The design of this package is to reduce the total suspended solids in the blow down water of the cooling tower. The total suspended solids and debris in the system, leads to less fouling in the cooling tower system. Decreasing the suspended solids can also help reduce biological growth in the system because suspended solids are a good source of food for microbiological organisms. Decreasing biological growth in turn helps to reduce microbiologically influenced corrosion. In addition, scaling can be reduced from side stream filtration by limiting fouling and corrosion by-products which can also contribute to scale formation on the heat exchange resulting in moderate to significant energy and water savings.

Side stream filters, continuously filters $100 \mathrm{~m}^{3}$ of the blow-down water in the blowdown pit. It can improve the water quality to reduce water consumption and ensure efficiency of the cooling system.

In conclusion, in the proposed design of the filtration package the streams of boiler blowdown and saturator blowdown will accumulated with cooling tower blow down and will go into blowdown pit. These streams are also known as POC and COC water. After the blow down pit a pump with pressure of 7 bar-g will pump the water into the side stream filter to reduce the TSS of the water, as side stream filters won't reduce the TDS of the water a RO package have been designed after the side stream filtration package which will reduce the TDS of the water. The side stream filter package acts as a pre-treatment unit for the RO package. In order to determine whether or not the designed system work; Hysys model of the system has been simulated. From the simulation it has been derived that the package will work at the efficiency of $67 \%$ and will produce the total volume of $63 \mathrm{~m}^{3}$ of pure water with $97 \%$ purity, i.e. no sign of TDS and TSS in the pure water.

\section{REFERENCES}

1. Araner. COOLING TOWER: TYPES, WORK PROCESS AND INDUSTRIAL APPLICATION. (2019). [Blog] Araner.

2. Allianceforwaterefficiency.org. (2019). Cooling Tower Introduction.

3. Duan, X., Williamson , J., McMordie Stough, K. and Boyd, B. (2012). Side Stream Filtration for Cooling Towers . 2nd ed. [ebook] Washington : Federal Energy Management Program U.S. Department of Energy, pp.1-30.

4. Bibi, K. (2019). CHOOSING THE RIGHT COOLING TOWER FILTRATION SYSTEM. [ online] Evoqua.com.

5. Duan, X., Williamson , J., McMordie Stough, K. and Boyd, B. (2012). Side Stream Filtration for Cooling Towers . 2nd ed. [ebook] Washington : Federal Energy Management Program U.S. Department of Energy, pp.1-30.

6. JOUR Huichao, Zhang Lei, Fang, Hao, Guang, Ying, Niu, (2009), Review on Water Distribution of Cooling Tower in Power Station, IOP Conference Series : Earth and Environmental Science, pp. 1-10.

7. Kulkarni, S. and Goswami, A. (2015). Studies and Experimentation on Cooling Towers: A Review . IRJET, 2(5), pp.1-4.

8. John A.Dutton . (2018). Peng-Robinson EOS ( 1976). Phase Relation in Reservoir Engineering . PNG 520. pp. 1. 